\title{
CONSIDERAÇÕES SOBRE VERDADE EM TEMPOS DE FAKE NEWS
}

\author{
Rudá da Costa Perini ${ }^{\mathrm{a}}$ \\ Vanise Gomes de Medeiros ${ }^{\mathrm{b}}$
}

\begin{abstract}
RESUMO
Neste artigo, almeja-se discutir o funcionamento da noção de verdade no discurso jornalístico. Para tanto, faremos um percurso filosófico, jornalístico e discursivo para refletir sobre a relação sujeito-língua-verdade-realidade com base na Análise do Discurso pecheuxtiana. Buscamos iluminar o modo como o discurso jornalístico se constitui socialmente como verdade e, além disso, problematizar a relação dual verdade-mentira.
\end{abstract}

PALAVRAS-CHAVE: Verdade; Análise do Discurso; Discurso jornalístico

Recebido em: 06/05/19

Aprovado em: 10/10/19

\section{A noção de verdade na perspectiva filosófica}

\section{A}

verdade é uma noção complexa, afetada por transformações sócio-históricas, atravessada por diversas contingências éticas, religiosas e políticas. Objeto da filosofia desde seus primórdios, ela vem sendo (re)construída

a Graduado em Letras pela UFF. Mestre em Estudos de Linguagem pelo PPGEL-UFF. Doutorando em Estudos de Linguagem pelo PPGEL-UFF com bolsa CAPES. Desenvolve pesquisa filiada à Análise do Discurso de perspectiva materialista com foco em discursos midiáticos e política.

b Professora associada da UFF, pesquisadora do CNPq, bolsista CNE FAPERJ. Atua nos campos da Análise de Discurso e da História das Ideias Linguísticas. 
com o passar dos séculos. Segundo Chauí (2008, p. 95), o que se entende hoje como verdade tem como ponto de partida possível três concepçóes distintas: a do ver-perceber, a do falar-dizer e a do crer-confiar. Essas três concepções, advindas do grego, latim e hebraico, seriam, respectivamente, alétheia, veritas e emunah.

A noção grega ${ }^{1}$ traz o ver-perceber, isto é, a manifestação do que realmente existe e se apresenta tal qual é, ao passo que o falso está acobertado. Dessa forma, o verdadeiro é o visível, a evidência (no sentido de ser aquilo de que se teria uma percepção total). A noção latina ${ }^{2}$ remete à capacidade intelectual e de memória daquele que relata, bem como à correspondência (ou não) entre o relato e o fato. Não depende da coisa em si, mas do relato, ou seja, de uma linguagem verdadeira. Por essa razão, é a concepção do falar-dizer. Seu oposto seria a mentira. Se, por um lado, as coisas podem ser reais ou imaginárias, por outro, os relatos e enunciados sobre elas é que são verdadeiros ou falsos. Já a noção advinda do hebraico ${ }^{3}$, a do crer-confiar, se liga, em certa

1 "Em grego, verdade se diz alétheia, palavra composta do prefixo a (que em grego indica 'negação') e de léthe (que significa esquecimento). Alétheia significa 'o não esquecido’ [...]. Por extensão do sentido alétheia também significa o não-escondido, não-dissimulado. Como não-esquecido, não-escondido, não-dissimulado a verdade é o que vemos numa contemplação, o que se manifesta ou se mostra para os olhos do corpo e do espírito. [...] Assim, a verdade é uma automanifestação da realidade ou manifestação dos seres à visão intelectual dos humanos. Ela é uma qualidade das próprias coisas (o manifestar-se ou mostrar-se a si mesma) e o verdadeiro está nas próprias coisas, quando o que elas manifestam é sua realidade própria. Conhecer é ver e dizer a verdade que está na própria realidade e, portanto, a verdade depende de que a realidade se manifeste, enquanto a falsidade depende de que ela se esconda ou dissimule em aparências. Por isso, na concepção grega, o verdadeiro é o ser (o que algo realmente é) e o falso é o parecer (o que algo aparenta ser e não é)” (CHAUÍ, 2008, p. 95-96, grifos da autora).

2 "Em latim, verdade se diz veritas e se refere à precisão, ao rigor e à exatidão de um relato, no qual se diz com detalhes, pormenores e fidelidade o que realmente aconteceu. Verdadeiro se refere, portanto, à linguagem como narrativa de fatos acontecidos, refere-se a enunciados que dizem fielmente as coisas tais como foram ou aconteceram. Um relato é veraz ou dotado de veracidade quando a linguagem enuncia fatos reais" (CHAUÍ, 2008, p. 96, grifo da autora).

3 "Em hebraico, verdade se diz emunah e significa 'confiança'. Agora são as pessoas e é Deus quem são verdadeiros. Um Deus verdadeiro ou um amigo verdadeiro são aqueles que cumprem o que prometem, são fiéis à palavra dada ou a um pacto feito; enfim, não traem a confiança. [...] A verdade é uma crença fundada na esperança e na confiança em uma promessa, estando referida ao futuro, ao que será ou virá. Sua forma mais elevada é a revelação divina e sua expressão mais perfeita é a profecia.” (CHAUÍ, 2008, p. 96, aspas e grifos da autora). 
medida, ao aspecto religioso. Mas também está relacionada a uma visão de futuro, de confiança no porvir. Logo, talvez se possa dizer que o que entendemos como verdade, hoje, seria uma síntese das três noções supracitadas, perpassada por certa temporalidade (passado-presente-futuro). Em suma,

[...] nossa concepção da verdade abrange $o$ que é (a realidade), $o$ que foi (os acontecimentos passados) e o que será (as ações acontecimentos futuros). Refere-se, portanto, à própria realidade (como na alétheia), à linguagem (como na veritas) e à confiança-esperança (como na emunah) (CHAUÍ, 2008, p. 96, grifos da autora).

Como aponta a autora, temos, atravessando a noção de verdade mais ou menos estável em nossa formação social, a tríplice realidade-linguagem-confiança. Para explorar melhor esse ponto, sigamos com Nietzsche. Esse filósofo, orientado pelo perspectivismo sobre a verdade, contesta a premissa positivista de que só há fatos - fenômenos em si mesmos. E nos diz que não há fatos, há interpretaçóes (NIETZSCHE, 1978, p. 304-305). Aqui, importa destacar o deslocamento que Nietzsche provoca na posição positivista sobre os fatos - os quais, para essa visão, são de ordem empírica -, elevando a reflexão sobre a perspectiva ao limite. Para o autor, quando estamos diante da realidade, não lidamos diretamente com os fatos (empíricos, em si), outrossim com nossa interpretação dos fatos. A crítica de Nietzsche recai sobre uma posição filosófica em que haveria uma busca vã pelo fenômeno em si, pela alétheia.

Nietzsche, ao postular a perspectiva das perspectivas, deixa a semente para pensarmos a questão do sentido, a saber: o objeto a ser significado (um texto, por exemplo) não somente possui mais de um sentido possível como, mais radicalmente, o próprio sentido se constrói no gesto de interpretação. Assim, não há sentido a priori para ser desvendado. É na interpretação que o sentido acontece. E isso tem paralelo com a formulaçáo de discurso dada por Pêcheux como efeito de sentidos entre locutores. Aproximando Nietzsche e Pêcheux, a interpretação pode ser compreendida como a força que confere sentidos, necessária ao processo de comunicação. Todo sentido é dado pela interpretação, sendo uma construção afetada por vários fatores (inconsciente e 
ideologia ${ }^{4}$ são dois que vale a pena mencionar), e não sendo, em si, imanente, uma verdade; "não buscar o sentido nas coisas: mas lhes impor!" (NIETZSCHE, 1978, p. 15, grifo do autor, tradução nossa). Assim, somos levados a questionar a ideia de objetividade, de evidência, de que o fato "fala por si só"; ideia correntemente traduzida na máxima positivista "contra fatos não há argumentos". Mas vamos com calma. Uma leitura apressada do autor poderia sugerir a inexistência completa dos fatos - uma vez que a significação do mundo se dá por meio de uma perspectiva. Não se trata disso. Neste ponto, concordamos com Camargo, haja vista que há interpretaçóes que precisam ser compreendidas como verdades, mas

Por mais que a realidade exista de forma independente ao homem, não haveria pensamento, conhecimento, filosofia, nem este debate sem ele [...]. Se tudo já existia antes dele e se continuará a existir depois, mesmo isto, só pode ser pensado a partir deste homem, isto é, perspectivamente. O pensamento é, assim como tudo o que o homem pode produzir, parcial e interpretativo, isto é, perspectivo. (CAMARGO, 2008, p. 106)

Por conseguinte, é possível direcionar essa reflexão para algo que nos interessa em particular: o texto. Ou seja, "um mesmo texto permite inúmeras interpretações: não existe a interpretação 'justa”" (NIETZSCHE, 1978, p. 120), mas certamente existem interpretações inválidas, isto é,

[...] não existe a interpretação verdadeira, mas existem interpretaçóes abusivas, arbitrárias, trapaceiras, baixas, rasteiras [...]. $\mathrm{O}$ fato de não haver uma perspectiva verdadeira não significa

4 Inconsciente e ideologia são conceitos dos quais a $\mathrm{AD}$ faz releitura por constituírem o processo de interpelação do sujeito. Inconsciente, noção advinda da psicanálise lacaniana, é o componente da psiquê que fica inacessível para o sujeito; o sujeito só o encontra na língua, aos tropeços, no lapso, no chiste, no ato falho, no sonho. Para Lacan, o inconsciente se estrutura como linguagem. Ideologia, noção trazida de Althusser, é o mecanismo que fabrica evidências para o sujeito ao mesmo tempo que apaga esse funcionamento; assim, produz a ilusão de colagem entre língua e mundo, naturalizando sentidos. 
que todas as interpretaçóes sejam igualmente válidas na interpretação da "realidade". É possível, pois, que existam interpretaçóes que falseiem o texto ao serem abusivas e arbitrárias em sua abordagem (CAMARGO, 2008, p. 108, aspas do autor)

É necessário recorrer ao discurso histórico já que o discurso jornalístico atua na construção do passado e na institucionalização dos sentidos. Por essa via encontra-se um convite a pensar a relação do historiador com o texto e com os fatos, pois a questão da interpretação abordada aqui, a partir da noção de verdade, pode, de certo ponto de vista, recair numa ideia de relativismo. Por esse motivo, temos de tomar todos os cuidados ao caminhar nesta linha tênue que se forma entre o pensar a realidade como um conjunto de construçóes de linguagem, consequentemente de interpretação, e o apagamento de fatos históricos via um suposto "vale tudo das interpretaçôes". Consoante Robin:

O trabalho historiográfico, entretanto, não é da ordem do pugilismo, mesmo verbal. Não consiste em argumentar para ganhar, em persuadir um adversário, mas em estabelecer um avanço cognitivo sobre tal ou tal tema, em função de um sistema de hipóteses e de questôes voltadas aos vestígios, aos documentos, a tudo aquilo que pode constituir arquivo, a partir dos quais, pelo cruzamento de dados, de novas hipóteses submetidas à documentação, verdades sempre parciais, mas fundas no real do passado, vão emergir. Em suma, o historiador coloca o verdadeiro sobre o real do passado. Ele não estabelece um sistema de argumentos à maneira dos sofistas, para ganhar custe o que custar (ROBIN, 2016, p. 271).

O que queremos apontar é precisamente o risco de reduzir a história ao que é da ordem da argumentação, da retórica, do discurso tipificado. Por este caminho poderíamos cair num apagamento da materialidade do acontecimento histórico, como se os fatos históricos não possuíssem sua espessura, seu 
peso e suas consequências - apesar de só ganharem sentidos na linguagem. ${ }^{7}$

Com Robin, vimos que não podemos negligenciar a interpretação dos fatos. Se mais de uma interpretação é possível, nem todas as interpretaçôes o são. Logo, há a interpretação que, pelas relaçóes de poder em jogo na sociedade, será tomada como verdade apagando outras possíveis, bem como há aquelas interpretaçóes "abusivas, arbitrárias, trapaceiras, baixas, rasteiras" (CAMARGO, 2008, p. 108). Há o revisionismo, o negacionismo, as fake news, e todo tipo de mentira cínica que pode igualmente ser tomada como verdade - pois, afinal, o sujeito, para ser sujeito, é interpelado pela ideologia, portanto, pode se identificar com a interpretação arbitrária, com o negacionismo, o charlatanismo histórico-filosófico, com a mentira.

\section{A noção de verdade no discurso jornalístico}

Avancemos, agora, para o discurso jornalístico. Podemos dizer que a perspectiva positivista denunciada por Nietzsche afeta a prática jornalística.

A visão positivista, muito em voga no meio científico do século XIX, influenciou decisivamente o olhar enviesado que, ainda no século XXI, muitos profissionais e pesquisadores da área lançam sobre a construção da informação. O "novo jornalismo", o "culto aos fatos" e, principalmente, o esforço hercúleo em tentar transformar o jornalismo em uma "máquina fotográfica da realidade" levou à defesa de uma objetividade idealista, cujas

7 A título de exemplo, Robin, a respeito do holocausto, retomando Evans (1997), adverte: “'Auschwitz 'não é discurso', dizia Evans, mas Auschwitz passa também no e pelo discurso, pela linguagem, pelos tropos, metáforas, estruturas narrativas e argumentativas, ritmos, escansôes. Deixar-se intimidar pelos negacionistas, repito, é fazer o seu jogo e empobrecer tanto o imaginário quanto a teoria, tanto o conhecimento quanto a transmissão. Certamente, a história - o texto histórico - não é ficção. Ela obedece às suas próprias regras. Ela não tem de imitar o horror dos fatos que relata e analisa, não tem de simular as características de seu objeto. Mas o historiador não pode evitar de se colocar a questão a respeito de sua escritura, dos procedimentos que ele aplica, a forma com que ele se situa no seu texto, com que ele dá voz aos outros, nesse caso as testemunhas ou os mortos" (ROBIN, 2016, p. 288, aspas da autora). 
premissas de "isenção", "imparcialidade" e "neutralidade" compóem, na verdade, o discurso dominante em uma sociedade concreta. Tal fenômeno pode ser identificado ao levarmos em conta a lógica da formação social capitalista, que aponta para uma profunda mercantilização das práticas sociais. (MENEZES, 2017 , p. 14 , aspas do autor)

É coerente a associação do "culto aos fatos", do qual nos fala Menezes, não só à herança positivista, mas também à lógica capitalista, tendo em vista que os jornais "vendem" algo que pode ser englobado na categoria geral de notícia, ou seja, a notícia é produto, e "a verdade de uma notícia, baluarte de um neoliberalismo (mercado livre de ideias) contemporâneo, se remete à fundamentação teórica da objetividade do acontecimento" (MEDINA, 1988, p. 20).

Entre as teorias do jornalismo, em consonância com Tavares (2015), mesmo nas mais recentes, que já questionam valores canônicos (verdade, objetividade, imparcialidade, credibilidade), a busca pela verdade parece estar enraizada:

Há assim duas dimensóes de jornalismo coexistindo em conflito: aquela tradicional, clássica, que se firma ainda na representação da realidade pela linguagem, e aquela que se deixa afetar pelos questionamentos típicos da modernidade, de impossibilidades impostas por limitaçôes do homem. Que a "verdade jornalística" seja, a um só tempo, prática e ideal, faz sentido precisamente nessas dimensóes. Enquanto na prática se reconhece a impossibilidade de se chegar a uma verdade por conta das limitaçôes do homem, a vontade de que isso fosse possível é colocada como horizonte ideal e orientação ética. (TAVARES, 2015, p. 34, grifos do autor)

O jornalismo enquanto instituição, segundo Franciscato (2005, p. 167), cumpre um papel social específico, não executado por outras instituiçôes. A instituição jornalística foi investida historicamente de legitimidade para reconstruir discursivamente uma realidade com base na ideia de 
fidelidade entre o relato e a ocorrência no mundo. É, pois, desse ponto de vista institucional que se situa a credibilidade do jornalismo. Credibilidade resultante (a) da compreensão (acordada em sociedade) de que o fazer jornalístico tem permissão para narrar os fatos; (b) de um percurso histórico dessa forma de conhecimento inscrita na trajetória da sociedade moderna e fundada em princípios relativamente consensuais na comunidade jornalística. Por conseguinte, apesar de, no seio das teorias jornalísticas, haver, há algum tempo, uma corrente que pensa criticamente a noção de verdade objetiva, ela sobrevive em um certo imaginário sobre o jornalismo. Por essa via, vimos com Guedes que

De uma maneira geral, está arraigada na sociedade a ideia de que o jornalismo tem a sua credibilidade enraizada na possibilidade de ser fiel na reprodução dos fatos. Nessa perspectiva, a conclamação de fontes, depoimentos e testemunhos considerados legítimos acabaria garantindo uma narrativa "pura" sobre o real, como se fosse possível eliminar a mediação [...] Nesse contexto, a linguagem e os jargóes jornalísticos se constituem nas principais ferramentas de persuasão social diante do mito da objetividade absoluta e da busca da verdade definitiva no jornalismo (GUEDES, 2009, p. 4-6, grifos do autor).

A fim de desdobrar este debate, trazemos a reflexão feita por Medeiros (2017) acerca do efeito verdade. Segundo a autora, a escrita literária no século XIX incorpora preceitos da escrita historiográfica, como o uso de referenciação a fontes para fornecer provas do que se narra. Nesse período, a escrita literária "indica um funcionamento que se aproxima da escrita historiográfica, isto é, um funcionamento que incide sobre a veracidade, daí efeito verdade" (MEDEIROS, 2017, p. 134). Medeiros parte de Ginsburg (2007) e Hartog (2013) para pensar sobre a problemática da verdade e sobre a noção de evidência.

Na esteira de Hartog, Medeiros sinaliza uma primeira noção de evidência ligada à visão, que Cícero, mais tarde, traduz como evidência. Outro sentido de evidência recuperado decorre do termo inglês evidence, que teria a ver com 
prova ou marca, com testemunho no sentido jurídico ou médico ${ }^{8}$. Contudo, Medeiros nos alerta: "o que se aponta como indícios e provas aí não são ainda o que a partir do século XVII começa-se a entender como fontes primárias e secundárias, fraturando assim, conforme Ginzburg, como se entendia a narrativa da história" (MEDEIROS, 2017, p. 136). Essa fratura pode ser entendida como uma quebra no paradigma do que se entende como evidência e, consequentemente, do que se compreende como verdade. Amarrando as pontas, a autora mostra que evidência se constrói, então, no discurso historiográfico, por meio de documentos, provas e arquivos. A referenciação passa a funcionar de modo a assegurar no texto um lugar de evidência, de garantia daquilo que seria verdadeiro. É parte dos procedimentos para dar suporte à verdade ${ }^{9}$, para possibilitar o efeito verdade.

A suposta verdade perseguida pelo jornalista, aquela que é supostamente narrada nos jornais, parece-nos funcionar de modo semelhante. Trata-se de um efeito verdade construído a partir do relato do jornalista muitas vezes ancorado em fontes, documentos, testemunhos, enfim, supostas evidências de que a notícia é verdade.

\section{A noção de verdade na perspectiva discursiva}

Da perspectiva discursiva, partimos do pressuposto de que não há uma verdade plena a ser descoberta em qualquer esfera de conhecimento. Contudo, contraditoriamente, há mentiras. O que tentamos problematizar, pois, é o próprio binômio verdade/mentira.

Nossa posição é a de que não há "a verdade”, mas interpretações relativamente estáveis sujeitas ao jogo de forças que tenciona o tecido social.

8 De natureza principalmente jurídica e judicial, mas também da área da medicina, esse registro tem sido utilizado pela história. Uma leitura dos primeiros capítulos de Tucídides é suficiente para fazer tal demonstração: não prescindindo, de modo algum de indícios e provas, ele define a história como pesquisa e investigação, busca da verdade (HARTOG, 2013, p. 13 apud MEDEIROS, 2017, p. 136).

9 Conforme Ginsburg, "os fatos têm existência extralinguística, e que a noção de verdade é parte de uma história muito longa, que coincide talvez com a história da espécie. Mas os processos usados para controlar e comunicar a verdade mudaram ao longo do tempo" (2007, p. 341). 
Em outras palavras, falamos de um efeito verdade constituído na linguagem, funcionando interdiscursivamente. Seguir essa orientação não caminha ao encontro de um relativismo radical no qual inexistem verdades, fatos, história e, portanto, todas as interpretaçóes são válidas. Pensamos a verdade como algo construído, um saber sócio-histórico-ideológico que possui sua própria materialidade - a espessura material do acontecimento. Logo, não há verdade fora da linguagem, fora de um sistema sociocultural, fora dos processos de significação; assim como não há verdade sem sujeito, interdiscurso e ideologia.

A fim de encaminhar a discussão para um fechamento, recorremos à noção de imaginário, visto que é nele que se fixam as interpretaçôes. O imaginário pode ser entendido como o (não)lugar onde se acomodam formaçôes imaginárias ${ }^{10}$. Com efeito, entendemos que sujeito consiste em uma posição que o indivíduo, interpelado pela ideologia, ocupa para dizer, uma "posição sujeito projetada no discurso" (ORLANDI, 2006, p. 17). Logo, para pensar algumas relaçóes (por exemplo, a relação sujeito-jornalista/sujeito-leitor) que se acomodam no imaginário, consideramos, com Mariani, que o sujeito se encontra

Imerso no efeito ilusório de uma linguagem transparente colocada a um mundo objetivo, decalcando-se em um pensamento previamente organizado e totalmente dizível, em que as palavras estariam representando coisas, para o sujeito configura-se obviamente possível descobrir a origem, a essência e determinar a literalidade dos sentidos (MARIANI, 1996, p. 33).

Muitas vezes, é evidente para o sujeito-leitor que o jornal narra a realidade. Por conseguinte, é, muitas vezes, evidente para o sujeito-jornalista sua objetividade instrumentalizada - ainda que já se admita no meio jornalístico não haver objetividade plena - para narrar os fatos como são (nesse gesto, incide a ilusão de transparência da língua, evidência produzida pelo funcionamento da ideologia). Esse é o funcionamento do jogo de imagens no discurso, ou seja,

10 Conforme Pêcheux ([1969] 1987, p. 82), trata-se de imagens projetadas entre sujeitos no discurso seguindo regras de projeção existentes em cada formação social. 
$O$ jornalista que enuncia tem uma imagem sobre si, seu papel e sua identidade. Essa imagem está alicerçada tanto em ideais como verdade e credibilidade quanto na consciência (às vezes nem tâo consciente assim, pois internalizada) sobre as condições de produção do discurso. O jornalista também tem uma imagem sobre seu leitor (BENETTI, 2008, p. 19).

Nesse jogo de projeçóes, a ideologia vai produzindo evidências (sentidos tomados como óbvios, como se estivessem sempre aí) e, simultaneamente, apaga seu funcionamento. Porém, a evidência pode ser questionada, pode não funcionar como evidência, as posiçôes podem mudar, pois há a possibilidade de contraidentificação, de resistência ao sentido estabilizado.

É na ilusão de transparência que o discurso jornalístico se sustenta ${ }^{11}$. Uma imagem sobre os jornais, acomodada no imaginário, faz com que seja uma evidência a isenção, a objetividade, a imparcialidade do sujeito-jornalista ao produzir a notícia, apagando que o mesmo assume uma determinada posição para dizer sobre fatos como elementos de uma suposta realidade objetiva. Isto é, não há uma realidade objetiva, pois:

O que chamamos de realidade é o resultado da construção/rememorialização cotidiana de concepçóes de mundo que não se inauguram nos sujeitos, mas que se concretizam em suas práticas sem que haja percepção crítica deste processo. A realidade, portanto, não é algo dado, um mundo externo, mas sim, algo que resulta da necessária significação com que o homem, ser simbólico, investe suas práticas sociais e linguageiras. E, assim, retornamos à produção de sentidos: ao dizer, o sujeito está sempre significando (ou interpretando a 'realidade'), retomando e

11 Para Mariani, “a imprensa não é o mundo, mas deve falar sobre esse mundo, retratá-lo, torná-lo compreensível para os leitores. O cotidiano e a história, apresentados nas diversas seçóes de um jornal, ganham sentido ao serem 'conectados' interdiscursivamente a um 'já-lá' dos assuntos em pauta. E essa interdiscursividade pode ser reconstruída através da análise dos processos parafrásticos presentes na cadeia intertextual que vai se construindo ao longo do tempo" (1996, p. 64, aspas da autora). 
renovando os processos de significação constitutivos de sua historicidade (MARIANI, 1996, p. 26, aspas da autora).

O sujeito, diante do sem sentido, por ser constitutivamente sujeito da linguagem, história, ideologia e do inconsciente, interpreta, dá sentido; diante do sem sentido há uma injunção a interpretar como condição primeira do trabalho simbólico com a linguagem. Não é possível, para o sujeito, não interpretar. A relação que se estabelece enquanto evidência entre fato (interpretado) e realidade (supostamente objetiva) é direta, como se o fato (interpretado) fosse a própria realidade em si mesma. Por esse motivo, o fato, mesmo existindo à revelia da interpretação, só é entendido como fato ao ser trabalhado pela interpretação; afinal, com Henry, aprendemos que "não há 'fato' ou 'evento' histórico que não faça sentido, que não peça interpretação, que não reclame que lhe achemos causas e consequências." (HENRY, 2014, p. 55, aspas do autor). Portanto, os fatos reclamam sentidos, assim não é possível para o sujeito ser objetivo, neutro ou imparcial justamente porque não há sujeito fora da língua, fora da ideologia e do inconsciente, fora da história, fora dos processos de significação construídos socialmente.

\section{Para fechar, uma provocação}

O objetivo central deste trabalho foi mostrar a dimensão problemática acerca da verdade. Para isto, com Chauí, tentamos capturar sentidos fundadores da noção de verdade que perpassam nossa formação social atual e avançamos na reflexão com o perspectivismo nietzschiano. Com ele, entendemos que não há "a Verdade", e com Robin, historiadora, compreendemos que nem toda interpretação é válida, e, sobretudo, que existe falseamento e mentiras. Em seguida, refletimos sobre a noção de verdade no discurso jornalístico, almejando desmontar o efeito de evidência que recobre noçóes como objetividade e neutralidade, ainda presentes no jornalismo, a despeito das reflexóes críticas feitas neste campo. Trouxemos, então, Ginsburg e Hartog, historiadores, que, ao encontro das reflexóes de Chauí, mostram como, ao longo dos séculos, a noção de verdade mudou e como se foram construindo procedimentos na escrita para produzir o efeito verdade, que também ocorrem no dis- 
curso jornalístico. Todo o trajeto de reflexóes feito converge para o território da Análise de Discurso. Sob as lentes dessa teoria, é possível olhar a noção de verdade como algo engendrado na/pela linguagem, descartando, vale salientar, as interpretações abusivas e os falseamentos das mais diferentes ordens.

Apesar de distantes estarmos de esgotar essa discussão, trazemos da LTI ${ }^{12}$ de Kemplerer (2009) uma reflexão que deixaremos como caminho a trilhar. Nosso ponto central é: se é possível afirmar a existência de verdades infalíveis, se pode, em contrapartida, falar em mentiras, o que nos leva a disjunção desse par paradigmático (verdade/mentira). Para isto, nos ateremos apenas a um aspecto trazido por Klemplerer, o estrangeirismo, para pensar em seu efeito na língua. Filólogo com escuta atenta à linguagem de seu tempo, Kemplerer registra, em seu diário, certas ocorrências linguísticas durante o período nazista: criação de abreviaturas, recorrência de certos prefixos, deslocamentos de sentidos e, a que daremos foco a seguir, a entrada de estrangeirismos. O autor observa no emprego de alguns estrangeirismos, como garant (fiador) e diffamieren (difamar), nuances de ordem prosódica, e, sobretudo semântica que convinham à LTI, pois tais palavras "por serem de origem estrangeira, talvez muita gente não as entendesse, sentindo-se mais impactadas justamente porque não compreendiam bem o significado" (KEMPLERER, 2009, p. 47). $\mathrm{O}$ que se tenta iluminar aqui é precisamente o funcionamento do estrangeirismo nas condições de produção de um regime totalitário, isto é, como um mecanismo de interdição ao dizer e ao dar sentido.

Discursivamente, são vários os funcionamentos do estrangeirismo (MEDEIROS, 2010). Ele trabalha o efeito de uma língua já estabilizada uma vez que se apresenta como advindo de outra língua; funciona como acréscimo, algo que viria completar uma lacuna, uma falta na língua, e assim tampona a existência de palavra que possa ser usada na língua. Tomemos como exemplo a profusão de fake news, termo de origem estadunidense, na conjuntura brasileira pré, durante e pós eleições de 2018. Fake news se sobrepóe ao termo mentira e seu uso tem várias implicaçôes. Uma delas é simular não haver outro termo e, ao mesmo tem-

12 LTI, a Lingua Tertii Imperii, ou a Linguagem do Terceiro Reich, é a uma expressão cunhada por Kemplerer (2009) para designar a linguagem que dominou a sociedade alemá durante o período nazista. 
po, funcionar no lugar dele (mentira), apagando sua força: Isto é fake news não equivale a Isto é mentira. Trabalha-se aí uma suposta equivalência que redobra a opacidade da língua ${ }^{13}$. Mas não só. Produz o efeito de pré-construído ${ }^{14}$, isto é, funciona como objeto do mundo, algo que "todo mundo sabe", silenciando o termo mentira ao adentrar como termo novo a preencher uma suposta lacuna.

Podemos, agora, traçar um paralelo com processos linguísticos apontados por Gadet e Pêcheux (2010) que irrompem durante as revoluçóes russa (1917) e francesa (1789). Os autores assinalam a entrada de neologismos, entre outros aspectos importantes do movimento na língua. "Em 1917, como em 1789, um enorme 'trabalho da língua' é posto em prática; as massas em revolução passam a falar” (GADET e PÊCHEUX, 2010, p. 65, aspas dos autores). Em Kemplerer, o funcionamento é outro: em lugar de as massas tomarem a palavra, como sinalizam Gadet e Pêcheux, ele nos mostra como a LTI cala as massas. Eis nossa provocação: estaríamos, na conjuntura brasileira atual, diante do despontar de uma nova linguagem ainda não nomeada? Uma linguagem marcadamente autoritária, excludente, violenta, beligerante que, à imagem e semelhança da LTI, se impóe para fazer calar as massas?

\section{Referências}

AUTHIER-REVUZ, J. Ces mots qui ne vont pas de soi. Paris: Larousse, 1995. BENETTI, M. O jornalismo como gênero discursivo. In: Revista Galáxia. São Paulo: Pontifícia Universidade Católica de São Paulo, n. 15: 13-28, jun. 2008. CAMARGO, G. A. Sobre o conceito de verdade em Nietzsche. In: Revista Trágica: estudos sobre Nietzsche. vol. 1, no 2: 93-112, 2008.

CHAUÍ, M. Convite à Filosofia. 13aed. São Paulo: Editora Ática, 2008.

EVANS, R. J. In Defense of History. Londres: Granta Books, 1997.

13 Se as palavras são opacas, na medida em que seus sentidos têm condiçôes de produçáo, um termo estrangeiro duplica a opacidade, pois seu significante, seguindo Authier-Revuz (1995), se desdobra sobre o signo.

$14 \mathrm{O}$ “[...] pré-construido, tal como o redefinimos, remete simultaneamente àquilo que todo mundo sabe', isto é, aos conteúdos de pensamento do 'sujeito universal' suporte da identificação e àquilo que todo mundo, em uma 'situação' dada, pode ser e entender, sob a forma de evidências do "contexto situacional"." (PÊCHEUX, 1988, 171-172, grifos e aspas do autor) 
FRANCISCATO, C. E. A fabricação do presente: como o jornalismo reformulou a experiência do tempo nas sociedades ocidentais. São Cristóvão: Editora UFS/Fundação Oviedo Teixeira, 2005.

GADET, F; PÊCHEUX, M. A lingua inatingivel: o discurso na história da linguística. Campinas: Editora RG, 2010.

GINSBURG, C. O fio e os rastros: verdadeiro, falso, fictício. São Paulo: Companhia das Letras, 2007.

GUEDES, N. G. T. Jornalismo e Construção Social da Realidade: uma reflexão sobre os desafios da produção jornalística contemporânea. In: ANAIS DO XXXII CONGRESSO BRASILEIRO DE CIÊNCIAS DA COMUNICAÇÃO, p. 1-15. Curitiba, 2009.

HARTOG, F. Evidência da história: o que os historiadores veem. Belo Horizonte: Autentica, 2013.

HENRY, P. A história não existe?. In: ORLANDI, Eni (org.). Gestos de leitura: da história no arquivo. $4^{\mathrm{a}}$ ed. Editora da Unicamp, 2014, p. 31-56.

KLEMPERER, V. LTI: a linguagem do Terceiro Reich. Rio de Janeiro: Contraponto, 2009.

MARIANI, B. S. C. O comunismo imaginário: práticas discursivas da imprensa sobre o PCB (1922-1989). 1996, 254 f. Tese (Doutorado em Linguística). Pós-Graduação em Estudos da Linguagem, Universidade Estadual de Campinas. Campinas: UNICAMP, 1996.

MEDEIROS, V. G. Uma reflexão sobre intervençôes dos escritores e o efeito verdade. In: Flores, G. G. B.; Gallo, S. M. L.; Lagazzi, S.; Neckel, N. R. M.; Pfeiffer, C. C.; Zoppi-Fontana, M. G. (org.). Análise de Discurso em Rede: Cultura e Mídia. 1a ed. Campinas: Pontes, 2017, v. 3, p. 131-142.

. Jornal, arquivo, instrumento linguístico. In: MEDEIROS, V.; MARIANI, B. (orgs.) Ideias linguísticas: formulação e circulação no período JK. RJ: FAPERJ; SP: RG, 2010, p. 85-107.

MEDINA, C. Notícia, um produto à venda: jornalismo na sociedade urbana e industrial. 2aed. São Paulo: Summus, 1988.

MENEZES, E. S. A possibilidade de inserção e aplicabilidade da análise de discurso na formação jornalistica: uma revisão teórica com vistas à análise da cobertura das eleiçóes presidenciais de 2014 no Brasil. 2017, 219 f. Tese (Doutorado em Linguística Aplicada). Programa de Pós-Graduação em Letras, Universidade Católica de Pelotas. Pelotas: PUC, 2017. 
NIETZSCHE, F. W. Fragments posthumes. Automne 1885 - automne 1887: Oeuvres philosophiques complètes, XII. Paris: Editions Galimard, 1978.

ORLANDI, E. P. Análise de Discurso. In: ORLANDI, E. P. Introdução às ciências da linguagem: discurso e textualidade. Campinas: Pontes Editores, 2006, p. 13-35. PÊCHEUX, M. Análise automática do Discurso (AAD-69). [1969] In: GADET, F.; HAK, T. (orgs.) Por uma análise automática do discurso: uma introdução à obra de Michel Pêcheux. $3^{\mathrm{a}}$ ed. Campinas: Editora da UNICAMP, 1997, p. 61-161.

. Semântica e discurso: uma crítica à afirmação do óbvio. [1975] 5a Ed. Campinas: Editora da Unicamp, 2014.

PERINI, R. C. A batalha do impeachment/golpe: os sentidos de um sítio bélico de significância no discurso jornalístico. 2019, 149f. Dissertação (Mestrado em Estudos de Linguagem). Pós-Graduação em Estudos de Linguagem, Universidade Federal Fluminense. Niterói: UFF, 2019.

ROBIN, R. Memória Saturada. Campinas: Editora da Unicamp, 2016.

TAVARES, L. As notícias e as coisas: para uma genealogia da verdade no jornalismo. 2015, 52f. Monografia (Graduação em Jornalismo). Centro de Comunicação e Expressão, Universidade Federal de Santa Catarina. Santa Catarina, 2015.

\title{
PONDERATIONS ABOUT TRUTH IN TIMES OF LIE
}

\begin{abstract}
This article aims to discuss the functioning of the notion of truth in journalistic discourse. To do so, we will take a philosophical, journalistic and discursive path to ponder on the subject-language-truth-reality relationship based on Pecheuxtian Discourse Analysis. We seek to shed light on the way in which journalistic discourse is socially constituted as truth and, in addition, to problematize the dual truth-lie relationship.
\end{abstract}

KEYWORDS: Truth; Discourse Analysis; Journalistic discourse. 